\title{
Relationships between in vitro lymphoproliferative responses and levels of contaminants in blood of free-ranging adult harbour seals (Phoca vitulina) from the North Sea
}

\author{
Aurélie Dupont ${ }^{\mathrm{a}}$, Ursula Siebert ${ }^{\mathrm{b}}$, Adrian Covaci ${ }^{\mathrm{c}, \mathrm{d}}$, Liesbeth Weijs ${ }^{\mathrm{c}, \mathrm{d}}$, Gauthier Eppe ${ }^{\mathrm{e}}$, \\ Cathy Debier ${ }^{\mathrm{f}}$, Marie-Claire De Pauw-Gillet ${ }^{\mathrm{g}}$, Krishna Das ${ }^{\mathrm{a}, *}$ \\ a Laboratory of Oceanology - MARE Center, University of Liège, B6c, allée de la chimie 3, B-4000 Liège (Sart-Tilman), Belgium \\ ${ }^{\mathrm{b}}$ Institute for Terrestrial and Aquatic Wildlife Research, University of Veterinary Medicine Hannover, Foundation, Werftstrasse 6, 25761 Buesum, Germany \\ ${ }^{\mathrm{c}}$ Toxicological Centre, University of Antwerp, Universiteitsplein 1, 2610 Wilrijk, Belgium \\ d Systemic Physiological \& Ecotoxicological Research (SPHERE), Department of Biology, University of Antwerp, Groenenborgerlaan 171, 2020 Antwerp, \\ Belgium \\ e Center for Analytical Research and Technology (CART), Inorganic Analytical Chemistry, University of Liège, B6c, allée de la chimie 3, B-4000 Liège \\ (Sart-Tilman), Belgium \\ ${ }^{\mathrm{f}}$ Unit of Nutrition Biochemistry, Catholic University of Leuven, Place Croix du Sud 2/8, 1348 Louvain-la-Neuve, Belgium \\ ${ }^{g}$ Mammalian Cell Culture Laboratory (GIGA-R), University of Liège, B6c, allée de la chimie 3, B-4000 Liège (Sart-Tilman), Belgium
}

\section{A R T I C L E I N F O}

\section{Article history:}

Received 22 January 2013

Received in revised form 18 August 2013

Accepted 24 August 2013

\section{Keywords:}

Phoca vitulina

Blood

Contaminant

In vitro

Lymphoproliferation

Immune parameters

\begin{abstract}
A B S T R A C T
In vitro culture of peripheral blood leucocytes (PBLs) is currently used in toxicological studies of marine mammals. However, blood cells of wild individuals are exposed in vivo to environmental contaminants before being isolated and exposed to contaminants in vitro. The aim of this study was to highlight potential relationships between blood contaminant levels and in vitro peripheral blood lymphocyte proliferation in free-ranging adult harbour seals (Phoca vitulina) from the North Sea. Blood samples of 18 individuals were analyzed for trace elements (Fe, $\mathrm{Zn}, \mathrm{Se}, \mathrm{Cu}, \mathrm{Hg}, \mathrm{Pb}, \mathrm{Cd}$ ) and persistent organic contaminants and metabolites ( $\Sigma$ PCBs, $\Sigma$ HO-PCBs, $\Sigma$ PBDEs, 2-MeO-BDE68 and 6-MeO-BDE47, EDDXs, hexachlorobenzene, oxychlordane, trans-nonachlor, pentachlorophenol and tribromoanisole). The same samples were used to determine the haematology profiles, cell numbers and viability, as well as the in vitro ConA-induced lymphocyte proliferation expressed as a stimulation index (SI). Correlation tests (Bravais-Pearson) and Principal Component Analysis with multiple regression revealed no statistically significant relationship between the lymphocyte SI and the contaminants studied. However, the number of lymphocytes per millilitre of whole blood appeared to be negatively correlated to pentachlorophenol $(r=-0.63, p=0.005)$. In adult harbour seals, the interindividual variations of in vitro lymphocyte proliferation did not appear to be directly linked to pollutant levels present in the blood, and it is likely that other factors such as age, life history, or physiological parameters have an influence. In a general manner, experiments with in vitro immune cell cultures of wild marine mammals should be designed so as to minimize confounding factors in which case they remain a valuable tool to study pollutant effects in vitro.
\end{abstract}

(C) 2013 Elsevier B.V. All rights reserved.

\section{Introduction}

During these last decades, large-scale mortalities of marine mammals have been increasingly documented (Greenland and Limpus, 2007; Osinga et al., 2012). Epizootics and mass stranding events have impacted numerous cetacean and pinniped species (Colegrove et al., 2005; de Swart et al., 1995a; Duignan et al., 1995;

\footnotetext{
* Corresponding author. Tel.: +32 0436633 21; fax: +32 043665147.

E-mail addresses: Krishna.das@ulg.ac.be, Aurelie.Dupont@gmail.com (K. Das).
}

Greenland and Limpus, 2007; Hanni et al., 1997; Lipscomb et al., 1996; Rogan et al., 1997). In 1988 and 2002, two major epizootics due to the phocine distemper virus (PDV) affected the harbour seal (Phoca vitulina vitulina) population inhabiting the North Sea (Härkönen et al., 2006; Müller et al., 2004). The population of the Wadden Sea situated along the east and south-east coasts of the North Sea, suffered losses up to approximately 57\% and $47 \%$ in 1988 and 2002, respectively (Dietz et al., 1989; Härkönen et al., 2006). As a consequence, these mass die-offs have initiated numerous pathological and toxicological studies (Das et al., 2008; de Swart et al., 1996; Ross et al., 1996b; Siebert et al., 2007, 2012) 
that notably discussed the impact of environmental pollutants on marine mammal health. Indeed, seals are exposed to a variety of anthropogenic contaminants mainly through their diet. As top predators, they are particularly at risk for bioaccumulating contaminants that biomagnify up the trophic food chain (De Guise et al., 2003). In fact, the chemical compounds known to bioaccumulate in harbour seal tissues are toxic trace elements including mercury (Hg) (Das et al., 2003) and persistent organic pollutants (POPs) such as organohalogenated compounds (polychlorinated biphenyls - PCBs), the dichlorodiphenyltrichloroethanes (DDTs), polybrominated diphenyl ethers (PBDEs), hexachlorobenzene (HCB) and chlordanes (O'Shea and Tanabe, 2003; Reijnders, 1980).

Evidence suggests that various immunotoxic contaminants (e.g. PCBs and metabolites) might have contributed at least partly to the severity and extent of the epizootics (Ross, 2002). Pollutants may indeed have toxic effects on peripheral blood leucocytes (PBLs), including lymphocytes, monocytes and granulocytes, thereby diminishing defenses against invading pathogens (Lahvis et al., 1995; Levin et al., 2007; Mos et al., 2006; Nakatsuru et al., 1985). Exposure to pollutants was hypothesized to be notably related to the high levels of parasitic or bacterial infections observed in seals found dead or killed due to severe illness before and after the 2002 epizootic (Siebert et al., 2007).

Blood sampling of marine mammals is considered as a convenient and minimally invasive method, relevant for the analyses of pollutants and biomarkers (Habran et al., 2011, 2013; Vanden Berghe et al., 2012), and for in vitro assays (Ross et al., 2003a). In vitro cultures of PBLs are indeed routinely used to assess the relationship between environmental contaminants and immune alterations in free-ranging marine mammals (Cámara Pellissó et al., 2008; De Guise et al., 1998; Kakuschke et al., 2008; Levin et al., 2005, 2007).

Organic and inorganic pollutants were analyzed recently in harbour seals from the North Sea revealing high concentrations compared to other species or locations (Das et al., 2008; Habran et al., 2013; Vanden Berghe et al., 2012; Weijs et al., 2009a,b,c). PCBs often exceed the threshold values of $20 \mathrm{ng}$ PCBs/g wet weight for seal blood (Weijs et al., 2009a) and of $17 \mu \mathrm{g}$ PCBs/g lipid weight for marine mammal blubber (Jepson et al., 2005; Siebert et al., 2012; Weijs et al., 2009b) above which deleterious effects might be observed (Kannan et al., 2000). No threshold has been documented for other compounds such as pesticides, brominated compounds or toxic metals in this species, but deleterious effects of POPs and metallic trace elements on the immune system have been documented in both in vivo and in vitro exposures in laboratory animals and wildlife (Cámara Pellissó et al., 2008; Dufresne et al., 2010; Kakuschke and Prange, 2007; Kakuschke et al., 2005; Luebke et al., 1997; Ross et al., 1996c). Associations have been established between environmental contaminants and immunotoxicity in freeranging seal populations (Das et al., 2008; de Swart et al., 1996; Dufresne et al., 2010; Ross et al., 1996a,b,c; van Loveren et al., 2000) as demonstrated for instance by significant impairment of natural killer cell activity and specific T-lymphocyte responses in vitro (Ross et al., 1996b). Nevertheless, the current knowledge of those cellular effects remains fragmentary. Moreover, the influence that the blood contaminants present in free-ranging harbour seals may have on in vitro immune responses once PBLs are isolated and cultured in controlled conditions is unknown. This point is highly relevant when cell viability and proliferation are evaluated in the framework of in vitro exposure to contaminants.

The present study aims to highlight potential relationships between blood pollutant levels and in vitro immune responses of free-ranging adult harbour seal from the North Sea. We determined the in vitro mitogen-induced lymphocyte proliferation and a broad range of blood parameters including haematology profiles, lymphocyte numbers and viability, essential element concentrations as well as non-essential element, persistent organic pollutant (POP) and naturally-produced methoxylated polybrominated diphenyl ether (MeO-PBDE) levels.

\section{Material and methods}

\subsection{Blood sample collection and conservation}

Blood samples were collected from 18 free-ranging harbour seals caught on sandbanks of the German part of the Wadden Sea: 3 from Kolumbus Loch (geographical coordinates $54^{\circ} 23^{\prime} \mathrm{N}$ and $8^{\circ} 35^{\prime} \mathrm{E}$ ) in April (spring) 2010; and 15 on Lorenzenplate (54 $25^{\prime} \mathrm{N}$ and $8^{\circ} 38^{\prime} \mathrm{E}$ ) in September (autumn) 2010 and April (spring) 2011 (Fig. 1). Seals were captured in seine nets at inter-tidal haul-out sites. They were transferred to individual tube nets and restrained manually for clinical examination. Sex, length and weight were determined before blood samplings (Table 1). Collection procedures were designed to preserve sample integrity and minimize sample contamination during processing and handling. All sampled animals were considered older than 3 years (adults) based on length and weight (Weijs et al., 2009b). During the sampling procedure, the animals were continuously under care of two experienced veterinarians. All individuals were released at the site of capture after completing the investigations. The maximum detention time, between the transfer of all animals in tube nets and the release of the last one, was one hour. All animals appeared healthy by veterinary check. They were in normal nutritional status and showed no sign of disease. The field studies were carried out under the relevant permits of the National Park Office Schleswig-Holstein and the animal experiment permit (AZ 312-72241.121-19).

Blood was drawn from the extradural venous sinus into sterile evacuated blood collection tubes using a $20 \mathrm{ml}$ syringe and a $1.2 \mathrm{~mm} \times 100 \mathrm{~mm}$ needle (Carromco, Hamburg-Norderstedt, Germany). Blood was transferred into serum tubes S-Monovette ${ }^{\circledR}$ for POP analysis and in $7.5 \mathrm{ml} \mathrm{S}$-Monovette ${ }^{\circledR}$ tubes treated with Lithium-Heparin (LH) for trace metal analysis (Sarstedt, Essen, Belgium). Serum for POP analysis was isolated by centrifugation at $1500 \times \mathrm{g}$ for $20 \mathrm{~min}$ at $21^{\circ} \mathrm{C}$ (Multifuge $3 \mathrm{~S}-\mathrm{R}$, Kendro, Hamburg, Germany). Whole blood ( $2 \mathrm{ml}$ ) and serum samples $(2 \mathrm{ml})$ were stored at $-20^{\circ} \mathrm{C}$ until analysis.

Blood samplings were also used to test the in vitro lymphocyte proliferation. Blood (15-30 ml) was collected in Cell Preparation Tubes with Sodium Heparin $\left(\mathrm{CPT}^{\mathrm{TM}}{ }^{\mathrm{M}}\right.$, BD Vacutainer ${ }^{\circledR}$, Plymouth, UK) that were gently inverted 10 times and stored upright at room temperature until further processing, within maximum $5 \mathrm{~h}$ of blood collection. Additional blood samples were taken to determine the clinical blood chemistry and haematology profiles, and other health parameters as part of an ongoing health monitoring.

\subsection{Haematological profiles}

The haematology profiles (white blood cells [WBC], red blood cells [RBC], haemoglobin [HGB], hematocrit [HCT], platelets [PLT]) were determined for all whole blood samples (before PBL isolation) using a scil Vet abc haematology analyzer (scil Animal Care Company GmbH, D-68519 Viernheim, Germany) which was calibrated for seal blood (Hasselmeier et al., 2008).

\subsection{PBL isolation and conservation}

PBLs were isolated according to the principle of density gradient centrifugation on Ficoll Hypaque ${ }^{\mathrm{TM}}$ (density: $1.077 \mathrm{~g} / \mathrm{ml}$ ) contained in $\mathrm{CPT}^{\mathrm{TM}}$ (BD Vacutainer ${ }^{\circledR}$ ), using a modified protocol described by de Swart et al. (1993). The blood samples contained in $\mathrm{CPT}^{\mathrm{TM}}$ (BD Vacutainer ${ }^{\circledR}$ ) were centrifuged at $1800 \times \mathrm{g}$ for $30 \mathrm{~min}$ at room temperature $\left(20^{\circ} \mathrm{C}\right)$. Cells were then resuspended into the plasma 


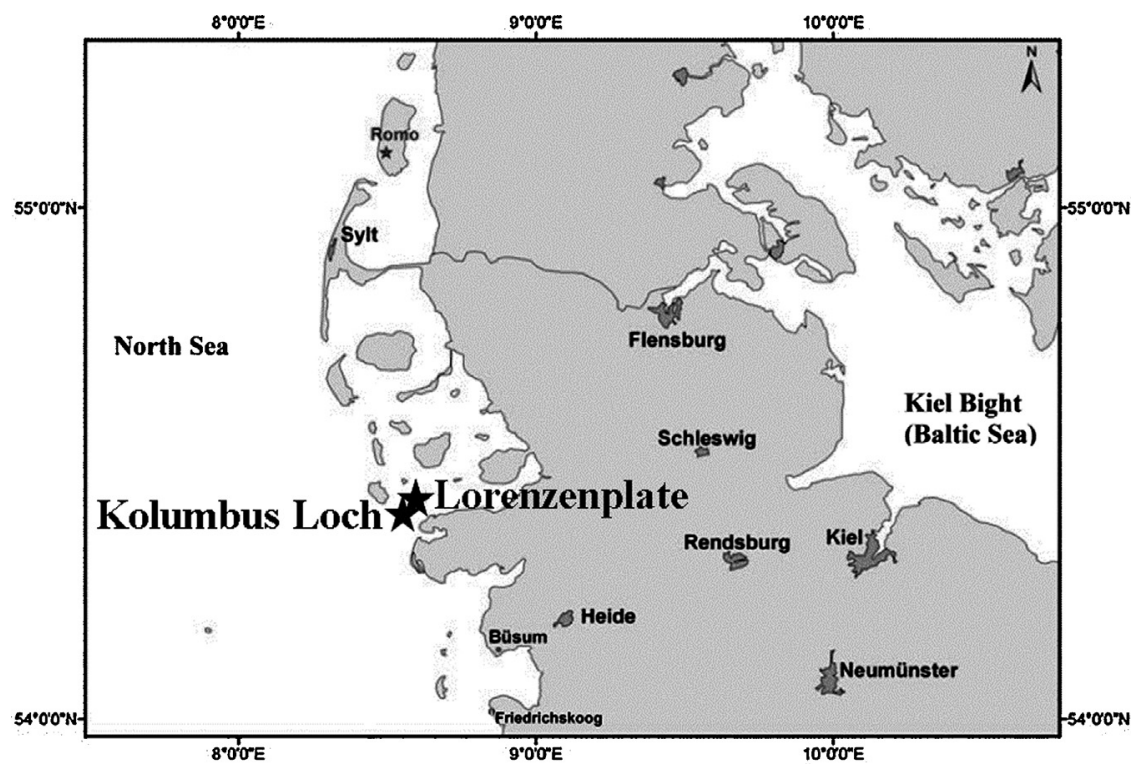

Fig. 1. The sampling sites Lorenzenplate and Kolumbus Loch are sandbanks of the Wadden Sea offshore of Germany. They are marked by stars ( $\star$ ).

by 10 gentle inversions to improve cell viability during transportation at room temperature, as advised by the manufacturer (BD Benelux N.V., Erembodegem, Belgium). The Ficoll Hypaque ${ }^{\mathrm{TM}}$ density fluid contained in CPTubes ${ }^{\mathrm{TM}}$ (BD Vacutainer ${ }^{\circledR}$ ) is originally used to separate peripheral blood mononuclear cells (PBMCs, including lymphocytes and monocytes) and plasma from granulocytes and erythrocytes. However, flow cytometry scatter plots of cell suspensions indicated that all leucocyte subpopulations (i.e., lymphocytes, monocytes and granulocytes) were present (see point 2.4, Fig. 2). After transportation to the cell culture laboratory within $18 \mathrm{~h}$, the PBLs were pipetted into separated vessels and washed 3 times in phosphate buffered saline (PBS, sterile filtered, BioWhittaker ${ }^{\circledR}$, Lonza, Verviers, Belgium). Cells were suspended in RPMI 1640 medium (BioWhittaker ${ }^{\circledR}$, Lonza, Verviers, Belgium) supplemented with $10 \%$ foetal calf serum (Gibco ${ }^{\circledR}$, Invitrogen, Paisley, UK), 0.33\% L-alanyl-L-glutamine (GlutaMAX ${ }^{\mathrm{TM}}$, Gibco ${ }^{\circledR}$, Invitrogen, Paisley, UK), 1\% non-essential amino-acids (BioWhittaker, Lonza, Verviers, Belgium), 1\% Na pyruvate (BioWhittaker, Lonza, Verviers, Belgium) and $1 \%$ penicillin-streptomycin (100 IU and $100 \mu \mathrm{g} / \mathrm{ml}$, BioWhittaker, Lonza, Verviers, Belgium). This complete culture medium was further referred to as culture medium. The viability and number of cells were determined with a Nucleocounter ${ }^{\circledR} \mathrm{NC}$ $100^{\mathrm{TM}}$ (Chemometec, Allerød, Denmark). The NucleoCounter ${ }^{\circledR}$ is an integrated fluorescence microscope designed to detect signals from the fluorescent dye, propidium iodide (PI) bound to DNA of cells with compromised cell membranes. The cell viability of samples was determined using the total cell count (following a treatment rendering all the cell nuclei susceptible to staining) and the count of non-viable cells (ChemoMetec A/S, 2013). After counting, cells were centrifuged, and the pellet was resuspended in a determined volume of culture medium added with $10 \%$ DMSO (dimethyl sulfoxide, Sigma-Aldrich Chemie GmbH, Steinheim, Germany) at $4{ }^{\circ} \mathrm{C}$ to adjust their concentration to $10 \times 10^{6}$ viable cells $/ \mathrm{ml}$. The cell suspension was transferred into cryovials $(1 \mathrm{ml} / \mathrm{vial})$ and placed into a freezing container (Mr Frosty, Nalgene) at $-80^{\circ} \mathrm{C}$ during $24 \mathrm{~h}$, before being transferred in liquid nitrogen.

\subsection{PBL in vitro cultures}

PBL cryovials were quickly thawed and transferred into $50 \mathrm{ml}$ Falcon tubes containing $40 \mathrm{ml}$ of complete culture medium prewarmed at $37^{\circ} \mathrm{C}$. They were centrifuged at $300 \times \mathrm{g}$ during $10 \mathrm{~min}$,

Table 1

Harbour seal (Phoca vitulina) information ( $n=18 ; 7$ females (F) and 11 males (M)).

\begin{tabular}{|c|c|c|c|c|}
\hline Sampling period & Harbour seal number & Gender & Length $(\mathrm{cm})$ & Weight $(\mathrm{kg})$ \\
\hline \multirow[t]{3}{*}{ April 2010} & 1 & $\mathrm{~F}$ & 163 & 73.5 \\
\hline & 2 & $\mathrm{~F}$ & 168 & 92 \\
\hline & 3 & $\mathrm{~F}$ & 170 & 96 \\
\hline \multirow[t]{7}{*}{ September 2010} & 4 & $\mathrm{~F}$ & 150 & 54.5 \\
\hline & 5 & $\mathrm{~F}$ & 158 & 61 \\
\hline & 6 & M & 160 & 66.5 \\
\hline & 7 & M & 160 & 63.5 \\
\hline & 8 & M & 166 & 67.5 \\
\hline & 9 & $\mathrm{~F}$ & 167 & 79 \\
\hline & 10 & M & 170 & 63.5 \\
\hline \multirow[t]{8}{*}{ April 2011} & 11 & M & 148 & 35 \\
\hline & 12 & M & 149 & 43 \\
\hline & 13 & M & 160 & 52.5 \\
\hline & 14 & M & 162 & 45 \\
\hline & 15 & M & 163 & 85.5 \\
\hline & 16 & M & 170 & 45 \\
\hline & 17 & $\mathrm{~F}$ & 170 & 82.5 \\
\hline & 18 & M & 179 & 102.5 \\
\hline
\end{tabular}




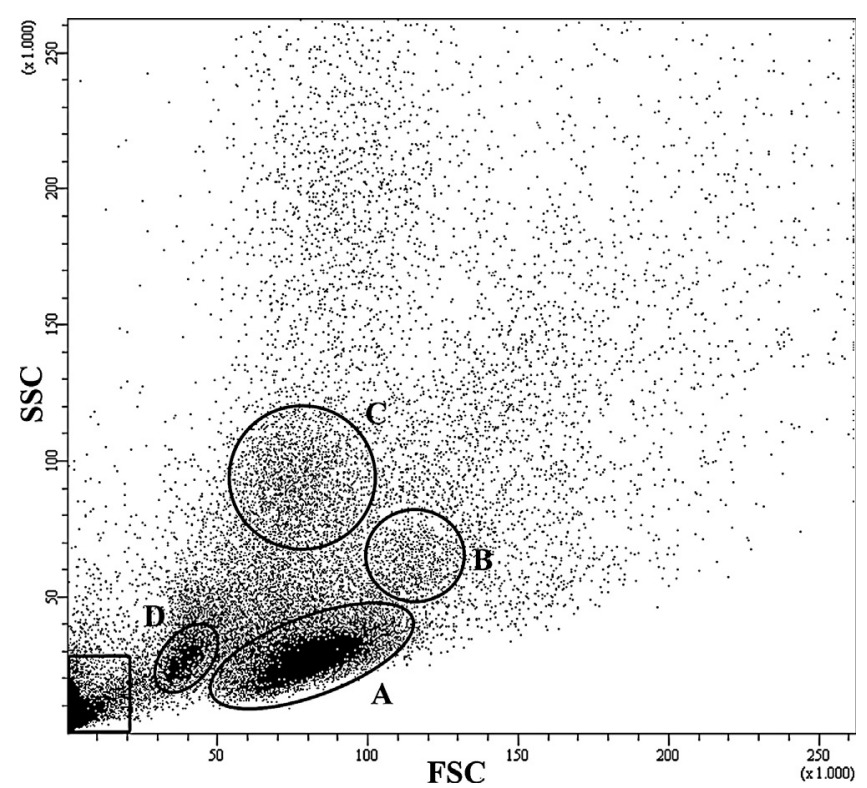

Fig. 2. Flow cytometry scatter plot of cell populations obtained after whole blood centrifugation in $\mathrm{CPT}^{\mathrm{TM}}$. Four subpopulations were gated based on forward scatter (FSC - size) and side scatter (SSC - internal complexity) characteristics. The gate A most likely includes lymphocytes. Gates B and C probably include monocytes and neutrophils, respectively. Gate D predominantly includes early apoptotic and dead cells, and the square in the left corner includes cell debris.

the supernatant was discarded and the cell pellet was resuspended in warm culture medium. Monocytes were partially depleted by plastic adherence in tissue culture flasks (Vented Cap, Sarstedt, Newton, NC, USA) incubated during $1 \mathrm{~h}$ at $37^{\circ} \mathrm{C}$ in a humidified atmosphere enriched with $5 \% \mathrm{CO}_{2}$. The cell suspension was harvested, the living cells were counted with a nucleocounter@ (Chemometec, Allerød, Denmark) and the concentration was adjusted to $1 \times 10^{6}$ cells $/ \mathrm{ml}$ (final concentration). Cells were also co-stained with propidium iodide (PI) and Annexin V-fluorescein isothiocyanate (FITC) conjugate according to the manufacturer's instructions (Annexin V: FITC Apoptosis Detection Kit I, BD, Erembodegem, Belgium) and analyzed by flow cytometry in order to determine the proportions of viable, early apoptotic and dead cells (in late apoptosis and necrosis). The Annexin V assay was used to detect phospatidylserine translocation on the membrane surface of cells undergoing apoptosis (Vermes et al., 1995). Cells were displayed as scatter plots based on their sizes, estimated by forward scatter (FSC), and internal complexity (granulosity), estimated by side scatter (SSC). The analysis was conducted with a FACSCanto ${ }^{\mathrm{TM}}$ II (BD, Erembodegem, Belgium) flow cytometer. The light source used was an air-cooled laser tuned to $488 \mathrm{~nm}$. FITC-fluorescence (FL1) was collected through a $502 \mathrm{~nm}$ long pass (LP) filter and then through a 530/30 nm bandpass filter, and PI fluorescence through a 585/42 nm LP filter (FL2), and through 655 and $670 \mathrm{~nm}$ LP filters (680 nm, FL3). Five-parameter (FSC-A, SSC-A, FL1, FL2, and FL3) data of minimum 50,000 events were collected and analyzed for each sample using FACS Diva software version 6.1.2. Scatter plots obtained by flow cytometry showed that all leucocyte subpopulations (i.e., lymphocytes, monocytes and granulocytes) were present, and that cell suspensions were composed of lymphocyteenriched leucocytes (Fig. 2). All cells were analyzed for AV-FITC and PI labelling. In all likelihood, the gate A included lymphocytes (mostly but not exclusively) as they are characterized by small sizes and low complexity compared to the other leucocyte types (Fig. 2). However, the exact position and quantification of leucocyte subpopulations in scatter plots was not possible as no specific or suitable marker was available for harbour seal at the time of experiment. Monocyte and neutrophil (most abundant type of granulocyte) gates were thus hypothetically drawn (gates B and C in Fig. 2) based on sizes and complexity characteristics as well as on literature data (Pillet et al., 2002; Zharinov et al., 2006). The presence of monocytes (despite depletion) and granulocytes was confirmed by microscopy analysis of cells stained with Giemsa (Modified Solution, Fluka Chemika, Sigma-Aldrich, Steinheim, Germany)(data not shown). Lymphocyte-enriched leucocytes were further referred to as PBLs.

Proliferation to Concanavalin A (ConA, Sigma-Aldrich Chemie $\mathrm{GmbH}$, Steinheim, Germany), a T-cell-specific mitogen in harbour seals (de Swart et al., 1993), was assessed by culturing PBLs in a flat bottom 96-well plate (transparent, Sarstedt, Newton, NC, USA) at $2 \times 10^{5}$ cells in $200 \mu \mathrm{l}$ culture medium per well with an optimal concentration of $5 \mu \mathrm{g} / \mathrm{ml}$ ConA in an incubator at $37^{\circ} \mathrm{C}$ under humidified atmosphere enriched with $5 \% \mathrm{CO}_{2}$. Control PBLs were cultured in medium alone and each culture condition was in triplicate. The actively proliferating lymphocytes were assayed with bromodeoxyuridine (BrdU) incorporation into newly synthesized DNA (BrdU Proliferation Assay, Calbiochem ${ }^{\circledR}$, Overijse, Belgium). Two types of controls were used for the BrdU tests: blanks (culture medium alone) and background controls (cells without BrdU). Each culture condition was in triplicate. BrdU label was added to wells of the microtiter plate for the last $24 \mathrm{~h}$ of culture. After $72 \mathrm{~h}$ of incubation, cells were fixed, permeabilised and the DNA denatured to enable antibody ( $\mathrm{Ab}$ ) binding to the incorporated BrdU. Detector anti-BrdU monoclonal Ab was pipetted into the wells and allowed to incubate for $1 \mathrm{~h}$, during which time it binds to any incorporated BrdU. Unbound Ab was then washed away and horseradish peroxidase-conjugated goat anti-mouse was added to bind to the detector $\mathrm{Ab}$. The horseradish peroxidase catalyzed the conversion of the substrate to a blue product, which is then converted to yellow after the addition of the solution which stops the reaction. The intensity of the coloured reaction product, which is proportional to the amount of incorporated BrdU in the cells, was quantified by measuring the absorbance (optical density, OD) in each well using a spectrophotometric plate reader (PowerWave X, Bio-Tek Instruments, Inc., Winooski, VT, USA) at dual wavelength of $450-540 \mathrm{~nm}$. The signals of proliferating cells were significantly higher than the corresponding blanks and background controls. For each well OD, the average blank absorbance was subtracted. Lymphocyte proliferation was expressed as a stimulation index (SI), calculated as the ratio of the proliferation of mitogen-induced stimulated cells to that of cells cultured without mitogen (Levin et al., 2005).

\section{$\mathrm{SI}=\frac{\text { OD of stimulated cells }}{\text { OD of corresponding control }}$}

In addition, to confirm the presence of lymphoblasts in stimulated conditions and the lack of cytotoxicity in control wells, the corresponding cell suspensions were stained with PI and Annexin V (Annexin V: FITC Apoptosis Detection Kit I, BD, Erembodegem, Belgium) and analyzed by flow cytometry as described above.

\subsection{Chemical analysis}

\subsubsection{Trace elements}

After being lyophilized, approximately $200 \mathrm{mg}$ of homogenized whole blood powder were digested in Teflon jar with concentrated $\mathrm{HNO}_{3}, \mathrm{H}_{2} \mathrm{O}_{2}$ and ultrapure water (Milli-Q ${ }^{\circledR}$ ultrapure water for trace element analysis, Millipore, Billerica, MA, USA) in a microwave oven (20 min between 0 and $600 \mathrm{~W}$, ETHOS, Milestones). After cooling, samples were diluted to $50 \mathrm{ml}$ with Milli-Q water in a volumetric flask. The trace elements $\mathrm{Cd}, \mathrm{Fe}, \mathrm{Ni}, \mathrm{Cu}, \mathrm{Se}, \mathrm{Pb}$, and $\mathrm{Zn}$ were analyzed by Inductively Coupled Plasma-Mass Spectrometry (ICPMS, Elan DRC II, PerkinElmer, Shelton, USA). Total mercury (T-Hg) was determined by atomic absorption spectrophotometry with the Direct 
Mercury Analyzer (DMA80, Milestones, Sorisole, Italy). Concentrations are expressed in $\mu \mathrm{g} / \mathrm{g}$ dry weight (dw). Concurrent analyses of a set of certified reference materials (CRM) and of procedural blanks were repeated throughout each set to ensure method's accuracy and precision. The control materials used were Seronorm ${ }^{\mathrm{TM}}$ Human, Trace Element Whole Blood Level-3 (SERO AS, Billingstad, Norway) and DOLT-3, Dogfish Liver Certified Reference Material for Trace Elements (National Research Council Canada, Ontario, Canada). The handling and preparation procedures were identical for all samples and reference materials analyzed.

\subsubsection{Organic contaminants}

In all serum samples, 29 PCBs ( $\Sigma$ PCBs), 18 HO-PCBs ( $\Sigma$ HO-PCBs), 7 PBDEs ( $\Sigma$ PBDEs), 2 MeO-PBDEs (2-MeO-BDE68 and 6-MeOBDE47), $\Sigma$ DDXs (o,p'-DDT, p, $\mathrm{p}^{\prime}$-DDT and metabolites o, $\mathrm{p}^{\prime}$-DDD, p, $\mathrm{p}^{\prime}$-DDD and $\mathrm{p}, \mathrm{p}^{\prime}$-DDE), hexachlorobenzene (HCB), oxychlordane $(\mathrm{OxC})$, trans-nonachlor (TN), pentachlorophenol (PCP) and 2,4,6tribromoanisole (TBA) were targeted. More precisely, investigated PCBs were IUPAC numbers (\#) 28, 52, 74, 87, 95, 99, 101, 105, 110 , $118,128,138,146,149,153,156,170,171,172,174,177,180,183$, $187,194,199,196 / 203,206,209$. Targeted HO-PCB congeners were 3HO-CBs (\# 118, 138, 153 and 180), 4HO-CBs (\# 79, 107, 120, 127, 130, 146, 162, 163, 172, 177, 187, 193 and 208) and di-4HO-CB202. Analyzed PBDEs were IUPAC \# 28, 47, 99, 100, 153, 154 and 183.

The method for serum analysis was slightly adapted from the methods described previously (Weijs et al., 2009a). A volume of serum $(1.5 \mathrm{ml})$ was spiked with internal standards (PCB 143, BDE 77 and $4^{\prime}-\mathrm{HO}-\mathrm{CB} 159$ ), diluted 1:1 with Milli-Q water, mixed with formic acid, sonicated for $20 \mathrm{~min}$ and extracted using solid-phase extraction (SPE) cartridges ( $6 \mathrm{ml} / 500 \mathrm{mg}$ Oasis HLB, Waters). Elution was done by $10 \mathrm{ml}$ of $\mathrm{MeOH}$ :dichloromethane (DCM, 1:1). After evaporation to near dryness, the analytes were reconstituted in $500 \mu l$ hexane:DCM (1:1) and fractionated on silica SPE cartridges ( $3 \mathrm{ml} / 500 \mathrm{mg}$, Varian) topped with $200 \mathrm{mg}$ acid silica (44\%, w/w). A first fraction containing PCBs and PBDEs was eluted with $5 \mathrm{ml} \mathrm{hex-}$ ane, while the phenolic compounds were eluted in a second fraction with $6 \mathrm{ml}$ DCM $(1: 1, \mathrm{v} / \mathrm{v})$. Both fractions were evaporated to dryness. The first fraction was reconstituted in $100 \mu$ iso-octane, while the second fraction was derivatized for $30 \mathrm{~min}$ with diazomethane to form MeO-PCBs and MeO-PBDEs after which it was evaporated to dryness and reconstituted in $75 \mu$ iso-octane.

For the analysis of PBDEs and MeO-derivatives, a GC-MS operating in electron capture negative ionization (ECNI) mode was equipped with a $30 \mathrm{~m} \times 0.25 \mathrm{~mm} \times 0.25 \mu \mathrm{m}$ DB- 5 capillary column (J\&W Scientific, Folsom, CA, USA). The MS was used in the SIM mode with two ions monitored for each MeO-PCB congener in specific windows, while ions $m / z=79$ and 81 were monitored for MeO-PBDEs and for PBDEs during the entire run. For the PCB and organochlorine pesticides (OCP) analysis, a GC-MS operating in electron impact ionization (EI) mode was equipped with a $25 \mathrm{~m} \times 0.22 \mathrm{~mm} \times 0.25 \mu \mathrm{m}$ HT-8 capillary column (SGE). The MS was used in the SIM mode with two ions monitored for each PCB homologue group or individual OCP in specific windows. Multilevel calibration curves $\left(r^{2}>0.999\right)$ in the linear response interval of the detector were created for the quantification. Quality control (QC) was performed by regular analyses of procedural blanks, by random injection of standards, spiked samples and solvent blanks. The QC scheme is also assessed through regular participation to interlaboratory comparison exercises organized by AMAP (POPs in human serum). Obtained values were deviating with $<20 \%$ from consensus values. For analytes detected in procedural blanks, the mean procedural blank value was used for subtraction. After blank subtraction, the limit of quantification (LOQ) was set at 3 times the standard deviation of the procedural blank. For analytes not detected in procedural blanks (HO-PCBs and MeO-PBDEs), LOQs were calculated for a signal-to-noise ratio $=10$. Results were expressed on a per serum volume basis as the lipid fraction of serum is composed of more polar lipids when compared to subcutaneous fat or other organs (Henderson et al., 1994), and contains non-polar lipids (i.e. hexane-extractable fat) at lower levels (Debier et al., 2003). Expressing POP concentrations in serum on a lipid weight basis (i.e. hexane-extractable fat) would thus lead to an overestimation (Debier et al., 2003).

\subsection{Data analysis}

Statistical analysis was performed using Statistica 9.1. (StatSoft, Maisons-Alfort, France). Each culture condition was in triplicate for each individual. Optical density values (BrdU test) and cell counts were averaged for each individual, giving one mean value per culture condition. Coefficients of variations (CV) were calculated as the ratio of the standard deviation (SD) to the mean. Comparisons of the OD means of control and stimulated PBLs after the $72 \mathrm{~h}$ of incubation was assessed by the Wilcoxon test for paired samples. The normality of all data distribution was assessed by visual inspection and using the Shapiro-Wilk test. All data included length, weight, haematology values, cell numbers and viability, SI, essential and non-essential element levels, and persistent organic pollutant (POP) and naturally produced methoxylated polybrominated diphenyl ether (MeO-PBDE) levels. All values were log-transformed $\left(\log _{10}\right)$ to achieve normal distributions. Comparisons of the means of lymphocyte stimulation indexes between sexes, locations, seasons and years of sampling were performed using the Student's $t$ test (two-tailed), respecting the normality of distribution and equality of variances (Bartlett, $p>0.05$ ). When variances were unequal, the Satterthwaite's approximate $t$ test was used. The level of statistical significance was defined at $p<0.05$. When normality of distribution could not be achieved despite the log-transformation, the non-parametric Mann-Whitney $U$ test was used. As sample sizes were small ( $n<20$ for each group), the obtained $U$ values were compared to respective critical $U$ values (Appalachian State University, 2013).

For chemical element measurements, each value below LOQ was replaced with a value of $\mathrm{LOQ} / 2$ and used in the statistical tests.

In the other tests performed (correlation tests, Principal Component Analysis and regressions), pollutants with more than $50 \%$ of values $<$ LOQ were suppressed as most of their values were identical (LOQ/2), thus presenting a low variability. After log-transformation, none of the considered distributions differed significantly from normality as shown by the Shapiro-Wilk tests (all $W>0.897$ and $p>0.05$ ). Correlation tests (Bravais-Pearson) were used to investigate potential relationships between in vitro lymphoproliferative responses and peripheral blood contaminant and trace element concentrations two-by-two. Then, a more global approach was foreseen, considering pollutants as combined compounds as they can act as a mixture with synergic and antagonistic behaviours. A Principal Component Analysis (PCA) was realized in order to reduce the number of original pollutant variables. Then, the two first factor scores revealed by the PCA were used in a multiple regression test as the independent variables, with SI and lymphocyte numbers as dependant variables.

\section{Results}

\subsection{Levels of trace elements in whole blood}

Trace element levels were all above the detection limit except that for Cd, for which seven seals sampled in 2011 exhibited non detectable concentrations (Table 2). A general LOQ mean value was calculated for all individuals, and when some individuals presented concentrations below their own LOQ, their number was added 
Table 2

Medians, ranges (minima-maxima), and means \pm standard errors (SE) of trace elements expressed in $\mu \mathrm{g} / \mathrm{g}$ dw and in $\mu \mathrm{g} / \mathrm{l}\left({ }^{*} \mathrm{except}\right.$ Fe, in $\left.\mathrm{mg} / \mathrm{l}\right)$ of whole blood ( $n=18$ ).

\begin{tabular}{|c|c|c|c|c|c|c|}
\hline & \multicolumn{3}{|c|}{ Concentrations ( $\mu \mathrm{g} / \mathrm{g} \mathrm{dw}$ ) } & \multicolumn{3}{|c|}{ Concentrations $(\mu \mathrm{g} / \mathrm{l})$} \\
\hline & Median & Range & Mean \pm SE & Median & Range & Mean \pm SE \\
\hline $\mathrm{Fe}$ & 2682 & $2500-2822$ & $2658 \pm 20$ & $744^{*}$ & 647-1139* & $772 \pm 33^{*}$ \\
\hline $\mathrm{Zn}$ & 11.5 & $9.8-13.2$ & $11.4 \pm 0.2$ & 3167 & $2956-4318$ & $3276 \pm 88$ \\
\hline Se & 3.4 & $2.1-6.8$ & $3.6 \pm 0.2$ & 976 & $544-1884$ & $1020 \pm 69$ \\
\hline $\mathrm{Cu}$ & 2.7 & $2.3-3.4$ & $2.8 \pm 0.1$ & 757 & $595-1088$ & $801 \pm 36$ \\
\hline $\mathrm{Hg}$ & 1.1 & $0.7-1.5$ & $1.1 \pm 0.1$ & 305 & $167-661$ & $322 \pm 26$ \\
\hline $\mathrm{Pb}$ & 0.032 & $<0.028-0.043$ & $0029 \pm 0.003(9)$ & 8.9 & $<8.3-16.9$ & $8.6 \pm 1.0$ \\
\hline $\mathrm{Cd}$ & $<0.006$ & $<0.002-0.026$ & $<0.006 \pm 0.001(12)$ & $<1.8$ & $<0.6-8.5$ & $<1.8 \pm 0.5$ \\
\hline
\end{tabular}

between parentheses. For example, Cd presented 12 values below its LOQ of which 7 below its LOD. The essential trace elements exhibited minor variations in concentration levels, with relative standard deviation (RSD) values lower than $20 \%$ for $\mathrm{Fe}, \mathrm{Cu}$, and $\mathrm{Zn}$, and $28 \%$ for Se. Their RSD expressed greater interindividual variations with $32 \%$ for $\mathrm{T}-\mathrm{Hg}$, $55 \%$ for $\mathrm{Pb}$ and $142 \%$ for $\mathrm{Cd}$. The median $\mathrm{Se} / \mathrm{T}-\mathrm{Hg}$ molar ratio was 7.9 ( $\min .-\mathrm{max} .=4.7-17.6$ ).

No significant difference of medians (Mann-Whitney $U$ test) was observed between genders, seasons of sampling (springautumn) except for $\mathrm{Cd}$ and $\mathrm{Fe}(p<0.05)$, years of sampling (2010-2011) except for Cd ( $p<0.01)$, and places of sampling (KL-LP) except for $\mathrm{Zn}(p<0.01)$.

\subsection{Levels of POPs in serum}

Table 3 summarizes $\Sigma$ PCBs, $\Sigma$ HO-PCBs, $\Sigma$ DDXs, PCP, $\Sigma$ PBDEs, TBA, TN, OxC and HCB serum concentrations ( $\mathrm{pg} / \mathrm{ml}$ ). The contaminants found at the highest concentrations were PCBs, constituting $86 \%$ of the mean total POPs, followed by their hydroxylated metabolites HO-CBs, and total DDT ( $\Sigma$ DDXs) of which the contribution of p, $\mathrm{p}^{\prime}$-DDE was up to $93 \%$. The PCB profile of the 18 animals was CB $153>$ CB $138>$ CB $187>$ CB $146>$ CB 99. The HO-PCB profile was 4 -HO-CB $107>162>146>187$. The 4-HO-CB 107, one of the lowest chlorinated compounds, indeed accounted for $49 \%$ of the sum in average (min. 24-max. 58\%). Its median concentration was two times higher than that of 4-HO-CB 162 and ten times that of 4-HOCB 187. Some HO-PCBs (3-HO-CB 118, 4-HO-CB 127 and 3-HO-CB 180 ) were not found in any sample, while 4-HO-CB 79 and 4-HO-CB 193 were detected in less than $25 \%$ of all samples. The mean ratio $\Sigma$ HO-PCBs/ $\Sigma$ PCBs equalled 0.10 and there was a good correlation between the two groups of pollutants $\left(r^{2}=0.76\right)$.

For PBDEs, BDE 47 was the predominant congener followed by BDE 100 . Trans-nonachlor and oxychlordane levels appeared variable among individuals. Among extreme values, 6 individuals presented concentrations below or just above the LOQ and 3 animals sampled in September 2010 presented concentrations 10 times higher than the LOQ. HCB was $<$ LOQ in more than $65 \%$ of the samples analyzed. o,p'-DDT, o, p'-DDD, 4-diHO-CB202, 6-MeO-BDE 47 and 2'-MeO-BDE 68 were below LOQ for all individuals. One individual (harbour seal no. 7 - Table 1) displayed higher pollutant

Table 3

Medians, ranges (minima-maxima), and means \pm standard errors (SE) of organic pollutants measured in serum of harbour seals, expressed in $\mathrm{pg} / \mathrm{ml}(n=18)$.

\begin{tabular}{lccc}
\hline & Median $(\mathrm{pg} / \mathrm{ml})$ & Range $(\mathrm{pg} / \mathrm{ml})$ & Mean $\pm \mathrm{SE}(\mathrm{pg} / \mathrm{ml})$ \\
\hline$\Sigma$ PCBs & 28,863 & $7498-102,819$ & $34,315 \pm 6051$ \\
$\Sigma$ HO-PCBs & 2326 & $1269-4129$ & $2398 \pm 212$ \\
$\Sigma$ DDXs & 2234 & $649-6377$ & $2739 \pm 430$ \\
PCP & 134 & $62-293$ & $155 \pm 16$ \\
$\Sigma$ PBDEs & 94 & $46-249$ & $125 \pm 18$ \\
TBA & 79 & $33-166$ & $84 \pm 9$ \\
TN & 65 & $13-245$ & $92 \pm 18$ \\
OxC & 48 & $<10-262$ & $79 \pm 19$ \\
HCB & $<20$ & $<20-35$ & $<20 \pm 3$ \\
\hline
\end{tabular}

loads than the other individuals. Its $\Sigma$ PCBs concentration was on average 5.5 times higher than the one of the other animals, while its $\Sigma$ PBDEs level was on average 3 times higher than in the others.

No statistical difference of POP medians (Mann-Whitney $U$ test) was observed between males and females for PCB28 (trichlorobiphenyl), $\Sigma$ tetraCBs, $\Sigma$ pentaCBs, $\Sigma$ octaCBs, PCB 206 and 209 (nona- and deca-CB, respectively), HCB, $\Sigma$ HO-CB and PCP $(p>0.05)$. On the contrary, $\Sigma$ hexaCBs $(p=0.030), \Sigma$ heptaCBs $(p=0.046)$, $\Sigma$ PCBs $(p=0.046)$, OxC, TN, $\Sigma$ DDXs, $\Sigma$ BDEs and TBA had $p$ values $<0.05$.

No statistically significant difference was observed between the season and year of sampling, except for PCP $(p<0.01)$ and HCB $(p<0.05)$.

\subsection{Haematological profiles}

Median values were calculated taking the season of sampling into account as some haematological values vary with it (Table 4; Hasselmeier et al., 2008). Indeed, the Mann-Whitney $U$ test showed that the numbers of lymphocytes, monocytes, RBC and HCT were significantly different between the two seasons considered $(U<16$, $p<0.05$ ). The median values for spring were 7900 neutrophils per blood millilitre (min. 6400-max. 10,500), 1600 lymphocytes/ml (min. 900-max. 2300) and 500 monocytes/ml (min. 300-max. 900). In autumn, the median values were 6800 neutrophils per blood $\mathrm{ml}$ (min. 4400-max. 9400), 3000 lymphocytes/ml (min. 2500-max. 5400 ) and 200 monocytes/ml (min. 100-max. 200).

This distinction between seasons was helpful to adequately evaluate the health parameters linked to haematological profile, as compared to literature data (Hasselmeier et al., 2008).

\section{4. $P B L$ in vitro cultures}

The lymphocyte proliferation responses to in vitro ConA stimulation were characterized for 18 harbour seals from the same population after $72 \mathrm{~h}$ of incubation. The viability of cells isolated by density gradient centrifugation was always above $96.7 \%$ (median 98.9\%) after thawing. After $72 \mathrm{~h}$ of incubation, lymphocyte proliferation in presence of ConA was demonstrated by the BrdU test analysis. The flow cytometry AV-PI labelling tests showed that the majority of the lymphocytes were out of the apoptotic and necrotic pathways before and after the incubation periods.

As regards the stimulation index, no correlation between the latter and body length or weight was detected $(p>0.05)$. All data were pooled as there was no significant difference in stimulation indexes between genders, seasons, years and places of samplings. Despite a strong interindividual variability, lymphocytes of all individuals showed strong stimulation responses, with mean values reaching at least 3 times the one obtained for the corresponding control (Fig. 3). Optical density values were found to be $0.09 \pm 0.01$ (mean \pm SE; median: 0.07, min.-max.: 0.01-0.24) in unstimulated control, compared to ConA-stimulated conditions which average value was $0.9 \pm 0.08$ (mean $\pm S E$; median: 0.9, min.-max.: 0.3-1.5). 
Table 4

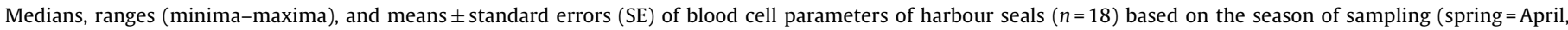
autumn = September). RBC = red blood cells; HGB = haemoglobin; HCT = haematocrit; PLT = platelets

\begin{tabular}{|c|c|c|c|c|c|c|}
\hline \multirow[t]{2}{*}{ Blood cell parameters } & \multicolumn{3}{|c|}{ Spring $(n=11)$} & \multicolumn{3}{|c|}{ Autumn $(n=7)$} \\
\hline & Median & Range & Mean \pm SE & Median & Range & Mean \pm SE \\
\hline Lymphocytes $(\mathrm{G} / \mathrm{l})^{* *}$ & 1.6 & $0.9-2.3$ & $1.6 \pm 0.04$ & 3.0 & $2.5-5.4$ & $3.5 \pm 0.2$ \\
\hline Monocytes $(\mathrm{G} / \mathrm{l})^{* *}$ & 0.5 & $0.3-0.9$ & $0.6 \pm 0.02$ & 0.2 & $0.1-0.2$ & $0.2 \pm 0.01$ \\
\hline Neutrophils (G/l) & 7.9 & $6.4-10.5$ & $8.3 \pm 0.13$ & 6.8 & $4.4-9.4$ & $6.8 \pm 0.2$ \\
\hline $\mathrm{RBC}$ (million $\left./ \mathrm{mm}^{3}\right)^{*}$ & 5.0 & $4.6-5.3$ & $5.0 \pm 0.02$ & 4.5 & $4.3-5.1$ & $4.6 \pm 0.04$ \\
\hline $\mathrm{HGB}(\mathrm{g} / \mathrm{dl})$ & 20.9 & $17.4-24.8$ & $21.1 \pm 0.2$ & 19.4 & $19.0-21.6$ & $20.2 \pm 0.2$ \\
\hline $\operatorname{HCT}(\%)^{* *}$ & 59.2 & $55.6-64.3$ & $59.5 \pm 0.2$ & 51.9 & $50.8-57.8$ & $53.9 \pm 0.5$ \\
\hline PLT (thousand/mm³) & 358 & $324-437$ & $372 \pm 4$ & 420 & $334-476$ & $416 \pm 6$ \\
\hline
\end{tabular}

* Significant difference: $U<16$, and $p<0.05$.

** Significant difference: $U<10$, and $p<0.01$.

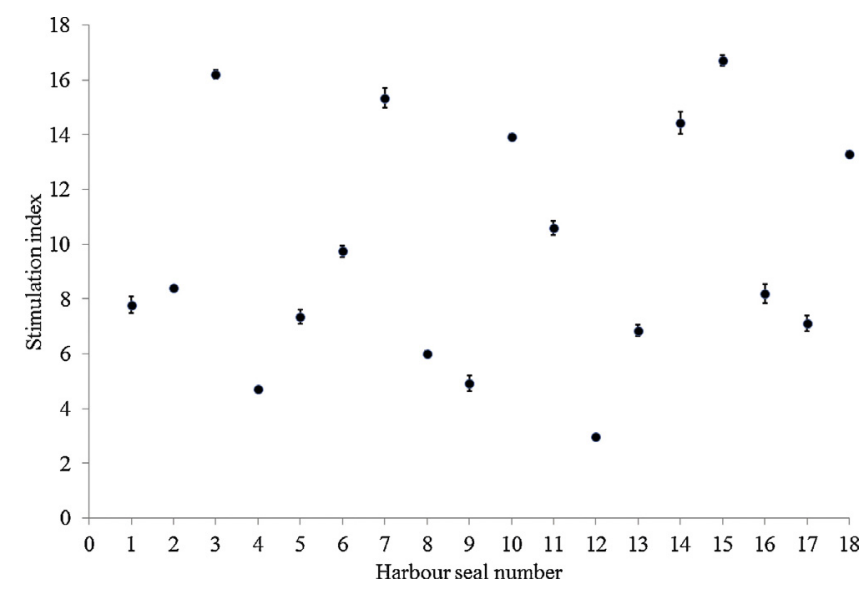

Fig. 3. Stimulation index (SI) mean values of triplicates with coefficient of variation bars for the BrdU proliferation assay of harbour seal lymphocytes after $72 \mathrm{~h}$ of incubation $(n=18)$.

\subsection{Relationships between lymphocyte parameters and contaminant levels}

Analyses of in vitro lymphocyte SI suggested no statistically significant correlation with the different trace elements, organic contaminant species and sums studied $(p>0.05$, e.g., correlation coefficient of SI and $\Sigma$ PCBs $=0.14, p=0.58$ ). On the other hand, the number of lymphocytes per $\mathrm{ml}$ of whole blood appeared negatively correlated to PCB $209(r=-0.51, p=0.03), 4-\mathrm{HO}-\mathrm{CB} 208(r=-0.53$, $p=0.02)$ and $\mathrm{PCP}(r=-0.63, p=0.005)$.

To further investigate those relationships, a PCA based on the correlation matrix was realized with the metallic pollutant $\mathrm{T}-\mathrm{Hg}$ and all sums of POP, except $\mathrm{Pb}$ and $\mathrm{HCB}$ for which at least $50 \%$ of values were $<\mathrm{LOQ}$ and were not normally distributed even after log-transformation. The correlation-based PCA revealed two principal components explaining $81.0 \%$ of the total variance. The two first component loads are summarized in Table 5. The variables

Table 5

Pollutant loads for the two first components of the PCA.

\begin{tabular}{|c|c|c|}
\hline & Component 1 & Component 2 \\
\hline $\mathrm{T}-\mathrm{Hg}(\log )$ & -0.49 & -0.71 \\
\hline$\Sigma$ PCBs (log) & 0.94 & -0.13 \\
\hline $\mathrm{OxC}(\log )$ & 0.94 & -0.04 \\
\hline $\mathrm{TN}(\log )$ & 0.97 & 0.07 \\
\hline$\Sigma D D X s(\log )$ & 0.97 & 0.03 \\
\hline$\Sigma$ PBDEs (log) & 0.97 & -0.02 \\
\hline$\Sigma$ HO-PCBs (log) & 0.86 & -0.46 \\
\hline PCP (log) & 0.30 & -0.50 \\
\hline TBA $(\log )$ & 0.41 & 0.68 \\
\hline Variance explained (cumulative) & $64.7 \%$ & $81.0 \%$ \\
\hline
\end{tabular}

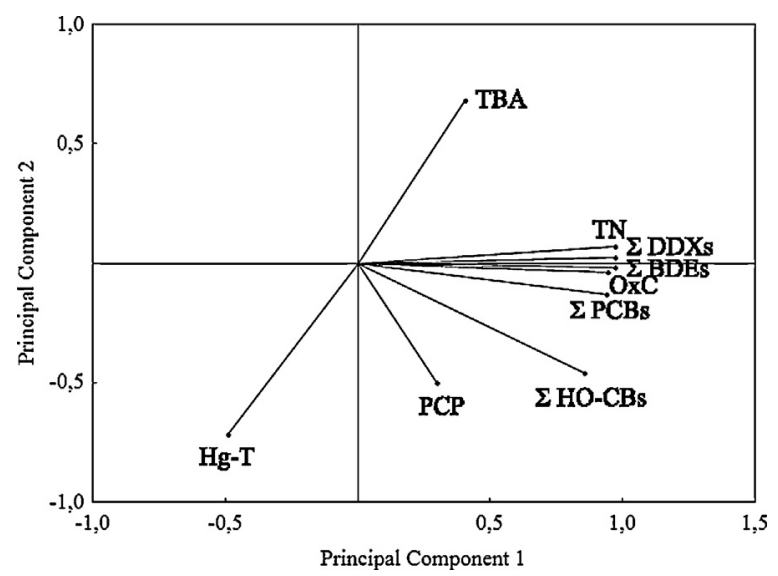

Fig. 4. PC1 and PC2 loading plot. The nine pollutant vectors of log-transformed concentrations represent the Bravais-Pearson correlations with the first and second principal components.

¿PCBs, OxC, TN, 5 DDXs, $\Sigma$ PBDE and $\Sigma$ HO-PCBs loaded principally in PC1 (all loadings positive and at least 0.86 ), whereas TBA loaded mostly on PC2 (loading=0.68). T-Hg loaded mostly on PC2 but presented a negative value. The loading plot (Fig. 4) highlighted distinctive features of $\mathrm{Hg}-\mathrm{T}$ and TBA compared to the other POPs of which blood levels were correlated with one another, indicating multiple exposure.

Multiple regressions of the two principal components with the lymphocyte stimulation index and number of lymphocytes per $\mathrm{ml}$ of whole blood revealed a significant positive correlation only between PC2 and lymphocyte numbers (Table 6, $p$-value $<0.05$ ).

A correlation test was also performed grouping the 3 dioxin-like PCB congeners (IUPAC \# 105, 118, 156) and the 26 non-dioxin-like PCB congeners (IUPAC \# 28, 52, 74, 87, 95, 99, 101, 110, 128, 138, $146,149,153,170,171,172,174,177,180,183,187,194,196 / 203$, $199,209)$ together. No significant correlation was found between the SI and one of those two groups ( $p=0.98$ and 0.58 , respectively), even when considering males and females separately.

Table 6

Multiple regression results for the relationship between the two first principal components of the PCA and the lymphocyte stimulation index (SI), and number of lymphocytes per blood millilitre $\left(\times 10^{6} / \mathrm{ml}\right)$.

\begin{tabular}{lccc}
\hline & & $t$-Value & $p$-Value \\
\hline SI $(\log )$ & Component 1 & 0.64 & 0.53 \\
& Component 2 & -0.84 & 0.41 \\
Lymphocyte number & Component 1 & 0.69 & 0.50 \\
$(\log )$ & Component 2 & 4.43 & 0.00 \\
\hline
\end{tabular}




\subsection{Relationships between body weight and contaminant levels}

The body weight was significantly correlated to $\mathrm{PCB} 99$ representing $65 \%$ of pentaCB $(r=-0.48, p=0.044)$, $\Sigma$ hexaCB, $\Sigma$ heptaCB, EoctaCB, PCB 206 (nonaCB) and 209 (decaCB), and $\Sigma$ PCBs $(r=-0.57, p=0.015), \Sigma D D X s(r=-0.53, p=0.025)$, BDE 100 and $\Sigma$ HO-PCBs $(r=0.5, p=0.04)$. Body weight was not significantly correlated to the SI $(p<0.05)$.

\section{Discussion}

During these last decades, the harbour seal population from the North Sea has been depleted by two epizootics caused by phocine distemper virus (Härkönen et al., 2006; Müller et al., 2004). Several studies have therefore investigated the health and presence of contaminants in harbour seals from this area (Reijnders, 1980, 1981; Siebert et al., 2012; Weijs et al., 2009b,c). Concomitant development of health monitoring programmes and in vitro assays circumvented the lack of experimental data about contaminant exposure and brought information on potential effects, as well as on biochemical pathways of toxic compounds (de Swart et al., 1995b,c; Ross, 2002; Ross et al., 2003a,b; Vos et al., 2003). The use of in vitro peripheral blood leucocytes offers a wide range of applications but one drawback is that these cells have already been exposed to a mixture of organic and inorganic contaminants in the blood of marine mammals. Indeed, harbour seals of the Wadden Sea displayed high blood levels of contaminants in the present study ( $\Sigma$ PCBs, $\Sigma$ HO-PCBs, $\Sigma$ DDXs and T-Hg) (Tables 2 and 3). Concentrations of organic contaminants ( $\Sigma$ PCBs, $\Sigma$ HO-PCBs $\Sigma$ DDXs, $\Sigma$ PBDEs, MeO-PBDEs) and trace elements ( $\mathrm{Hg}, \mathrm{Cd}, \mathrm{Pb}, \mathrm{Zn}, \mathrm{Cu}, \mathrm{Fe}$ ) analyzed in the blood of these 18 harbour seals are from the same order of magnitude than those found in the last few years in individuals from the same seal population (Das et al., 2008; Griesel et al., 2006, 2008; Kakuschke et al., 2008; Weijs et al., 2009a). The profile of PCBs (CB $153>$ CB $138>$ CB $187>$ CB $146>$ CB 99) analyzed in the serum was similar to that described previously for harbour seals collected between 2006 and 2008 in the same geographical area (Weijs et al., 2009a), and for grey seals from the North Sea where PCB 153 and 138 were the main contributors (Vanden Berghe et al., 2012).

Blood samples provide a window into an animal's complex network of immune function (De Guise, 2002). Haematology profiles of the 18 seals were comparable to a previous study on free-ranging and captive harbour seals from the Wadden Sea (Hasselmeier et al., 2008). However, the lymphocyte numbers in autumn were higher compared to the data given by Hasselmeier et al. (2008), but stay in the range given for spring. One individual (harbour seal number 4 - Pv4) presented a much higher autumn concentration with 5400 lymphocytes/ml. In all animals of this study, the erythrocyte haematology profile was generally more homogeneous than the leucocyte profile, which is more influenced by physiological changes (e.g., bacterial or viral diseases, stress) (Hasselmeier et al., 2008). The life histories of these individuals are unknown as they are living in the wild but it is known from pathological investigations that those free-ranging animals have mild infectious diseases, which explains the variability observed in blood leucocyte profiles (Siebert et al., 2007).

Lymphoproliferative response, as a specific T-cell response, can also give valuable information on the adaptive immune response. Despite the variability related to samples obtained from freeranging harbour seals, a clear stimulation of the $\mathrm{T}$ lymphocytes associated with a significant proliferation could be observed (Fig. 3). The in vitro stimulation index (SI), currently used in cell culture, showed significant interindividual variation. Nevertheless, high inter- and intra-individual variations of lymphocyte proliferation also occur in humans in which the whole life history is generally known, and in which homogeneous groups were tested (e.g. Stone et al., 2009). Our results did not highlight any clear correlation between the stimulation indices and the pollutants or class of pollutants studied (component 1 , Table 5). In contrast, a previous study showed that in vitro Con A-induced peripheral blood lymphocyte proliferation was inversely correlated to whole blood levels of tetra- to octa-CBs, p, $\mathrm{p}^{\prime}$-DDT, o, $\mathrm{p}^{\prime}$-DDE and p, $\mathrm{p}^{\prime}$-DDE in a small group $(n=5)$ of bottlenose dolphins (Tursiops truncatus) (Lahvis et al., 1995). However, the very small sample size and large age range of those animals (3-32 years old, approximate age) precluded drawing extensive conclusions. Studies on harbour seal pups highlighted modulating effects of PCBs from the blubber (Levin et al., 2005; Mos et al., 2006). Mos et al. (2006) showed that the proliferative responses of $\mathrm{T}$ lymphocytes, but not of B lymphocytes (mimicked by stimulation with the polyclonal activators ConA and lipopolysaccharide (LPS), respectively), were significantly decreased in harbour seal pups presenting higher PCB concentrations in their blubber. On the other hand, Levin et al. (2005) reported a significant body weight-independent positive correlation between both T-cell mitogen (phytohemagglutinin [PHA])- and B-cell mitogen (LPS)-induced lymphocyte proliferation and the blubber concentrations of $\Sigma 11$ PCBs, but no significant correlations were found between ConA-induced lymphocyte proliferation and total PCB concentration (Levin et al., 2005). However, the correlations observed between lymphocyte proliferation indices and blubber or blood PCB levels are different as these two tissues differ in $O C$ affinities and retention capacities. This is because their lipid composition is different and because contaminants have different lipophilic properties (Addison and Brodie, 1987; Sinjari et al., 1996), resulting in a selective retention of the more lipophilic compounds in the blubber and the more polar compounds in the blood (Lydersen et al., 2002).

In the framework of in vitro exposure to contaminants, Neale et al. (2002) showed no significant depression in harbour seal lymphoproliferation when exposed to $10 \mu \mathrm{M} \mathrm{CB}-156$ and CB-80. Other studies of in vitro exposure to some $\mathrm{OC}$ mixtures (PCBs and TCDD) have revealed significant positive correlations with the ConA-induced $\mathrm{T}$ cell proliferation in the harbour seal, Northern fur seal, Steller sea lion, beluga whale, Commerson's dolphin and sea otter (Levin et al., 2007; Mori et al., 2006). On the contrary, significant decreases in lymphocyte proliferation were seen after mercury exposure in harbour seals (Das et al., 2008; Dufresne et al., 2010) and after OC mixture exposure in mice (Mori et al., 2006), for example. The in vitro exposure of harbour seal granulocytes to $12 \mu \mathrm{M}$ of BDE-47, -99 and -153 had also been shown to induce a thiol depletion and phagocytosis inhibition (Frouin et al., 2010).

In the present study, the number of activated lymphocytes appeared significantly negatively correlated to only a few blood pollutants (PCB 209, 4-HO-CB208 and PCP) but this cannot be clearly discussed for PCB 209 and 4-HO-CB208 as they are minor compounds. In contrast, PCP, a widely used pesticide ubiquitous in the environment, had been demonstrated to have suppressive effects on human lymphocytes in vitro (Lang and MuellerRuchholtz, 1991) as well as on diverse cellular and humoral immune parameters (Daniel et al., 1995, 2001). Serum levels are not available for comparison in marine mammals, but humans usually present much lower concentrations (Butte and Heinzow, 1995). PCP should thus be monitored in marine mammals in order to find out more about its biological effects.

The fact that no clear correlation could be found between the in vitro SI and the contaminants present in blood of free-ranging adult harbour seals at that time of their annual cycle does not mean that chemicals have no toxic effect on PBLs. In all likelihood, there are more complex interactions between confounding factors explaining immunological variations observed in vitro. In any case, the 
results obtained in in vitro assays should be interpreted cautiously as PBLs are isolated from environmentally contaminated harbour seals. Generally speaking, factors such as precise age, nutritional status, genetic factors, stress, disease, nursing, or fasting, may have additional influences on immune functions, thereby limiting the direct ability to detect the effects of contaminants on the immune system (Levin et al., 2005). Those factors should thus be taken into consideration, within the realms of possibility. In this study, all individuals were adults in a good body condition, presenting no sign of disease. Yet minor injuries or infections and stress may have influenced the lymphocyte responses.

Furthermore, contaminants were measured in serum (organic pollutants) or whole blood (metals) and not in blubber or in liver, both tissues known to accumulate these contaminants over a lifetime (Weijs et al., 2011) in contrast to blood (Habran et al., 2013). However, correlations could be made between levels of organochlorines found in blood and blubber (Lydersen et al., 2002). Phocid seals regularly go through fasting or reduced food intake periods and most of their mass loss during these periods is derived from catabolism of lipids from their inner blubber layer (Nordoy and Blix, 1985). In harbour seals, the mobilization of lipids from the blubber notably occurs in individuals having lower food intake during the breeding and moulting seasons (Burns, 2008), in pups during the postweaning fast (Muelbert and Bowen, 1993) and in females producing milk (Boness et al., 1994). Lactation is indeed particularly demanding, leading to important loss of body fat and energy (Bowen et al., 1992). Blood samples from a seal which is in a state of positive energy balance would thus have POP levels reflecting those in the diet, while blood levels during fasting and lactating periods are reflecting inner blubber levels of bioaccumulated lipophilic contaminants. Moreover, seals in a prime condition generally have lower concentrations than animals in a poor condition (Lydersen et al., 2002). Harbour seals of this study were sampled while in a good condition before the breeding season and after the moulting season, and not while in a poor condition as during moult for example. Their blood levels could thus reflect low contaminant concentrations compared to those of fasting and milk production periods.

Results obtained in our study highlighted the fact that variations in proliferation could not be directly linked to the blood pollutants investigated in adult harbour seals in a good body condition, but that other factors could most likely have an influence. Field studies do thus allow the opportunity to study the direct and indirect effects of real-world exposures to POPs on the immune system when confounding factors are minimized (Levin et al., 2005).

\section{Conclusions}

We provide here a relevant approach to get a better understanding of the relationships between the immune function and several organic and inorganic contaminants present in the blood of freeranging adult harbour seals from the North Sea. This is the first study reporting the simultaneous measurement of blood haematology parameters, trace elements, PCBs, PBDEs, naturally produced MeO-PBDEs, DDXs, OxC, TN, HCB and the metabolites HO-PCBs, in blood of healthy harbour seals, concomitantly to the study of lymphocyte proliferation in vitro. Significant lymphocyte proliferation was observed and results highlighted a clear correlation between the number of lymphocytes per blood millilitre and PCP, but not between the lymphocyte stimulation indices and blood contaminant levels. This corroborates the fact that peripheral blood lymphocytes isolated from wild harbour seals and cultured in controlled conditions constitute a valuable tool for in vitro studies, as long as confounding factors are limited. Nevertheless, a study carried out on a bigger sample size would be necessary to confirm those results.

\section{Acknowledgements}

Aurélie Dupont was supported by a FRIA grant (Fonds pour la formation à la recherche dans l'industrie et dans l'agriculture). Krishna Das is a F.R.S. - FNRS Research Associate (Fonds de la Recherche Scientifique). This study was supported by the FRFC Grant \#2.4502.07 (F.R.S.-FNRS). The seal capture was conducted under the funding of the Ministry of Renewable Energies, Agriculture, Environment and Rural Areas of Schleswig-Holstein, Germany. Liesbeth Weijs and Adrian Covaci acknowledge financial support from FWO-Flanders (Foundation for Scientific Research). The authors wish to thank all people involved, for their help in the field trials, sampling and processing of blood analyses. The authors are also grateful to Renzo Biondo (Laboratory of Oceanology, ULg) for its valuable technical assistance in trace element analysis, and to Raafat Stephan for his help in flow cytometry (Imaging and Flow Cytometry platform, GIGA, ULg). This is a MARE publication.

\section{References}

Addison, R.F., Brodie, P.F., 1987. Transfer of organochlorine residues from blubbe through the circulatory system to milk in the lactating grey seal Halichoerus grypus. Can. J. Fish. Aquat. Sci. 44, 782-786.

Appalachian State University, 2013. Critical Values of the Mann-Whitney U (TwoTailed Testing) [Data file], Retrieved from: http://www.lesn.appstate.edu/ olson/stat_directory/Statistical\%20procedures/Mann_Whitney\%20U\%20Test/ Mann-Whitney\%20Table.pdf

Boness, D.J., Bowen, W.D., Oftedal, O.T., 1994. Evidence of a maternal foraging cycle resembling that of otariid seals in a small phocid, the harbor seal. Behav. Ecol. Sociobiol. 34, 95-104

Bowen, W.D., Oftedal, O.T., Boness, D.J., 1992. Mass and energy transfer during lactation in a small phocid, the harbor seal (Phoca vitulina). Physiol. Zool. 65, $844-866$.

Burns, J.J., 2008. Harbor seal and spotted seal Phoca vitulina and P. largha. In: Perrin, W.F., Wursig, B., Thewissen, J.G.M. (Eds.), Encyclopedia of Marine Mammals. second ed. Academic Press, San Diego, CA, pp. 533-542.

Butte, W., Heinzow, B., 1995. Referenzwerte der Konzentration an Pentachlorphenol in Serum und Urin (deutsch). Klinisches Labor 12, 31-35.

Cámara Pellissó, S., Muñoz, M.J., Carballo, M., Sánchez-Vizcaíno, J.M., 2008. Determination of the immunotoxic potential of heavy metals on the functional activity of bottlenose dolphin leucocytes in vitro. Vet. Immunol. Immunopathol. 121, 189-198.

ChemoMetec A/S, 2013. NucleoCounter NC-100 concept. Cell viability, Retrieved from: http://www.chemometec.com/en-GB/ Products/NucleoCounter-NC-100/NC-100-Concept/Cell-Viability

Colegrove, K.M., Greig, D.J., Gulland, F.M.D., 2005. Causes of live strandings of northern elephant seals (Mirounga angustirostris) and pacific harbor seals (Phoca vitulina) along the central California Coast, 1992-2001. Aquat. Mamm. 31, 1-10.

Daniel, V., Huber, W., Bauer, K., Opelz, G., 1995. Impaired in-vitro lymphocyte responses in patients with elevated pentachlorophenol (PCP) blood levels. Arch. Environ. Health 50, 287-292.

Daniel, V., Huber, W., Bauer, K., Suesal, C., Mytilineos, J., Melk, A., Conradt, C. Opelz, G., 2001. Association of elevated blood levels of pentachloropheno (PCP) with cellular and humoral immunodeficiencies. Arch. Environ. Health 56, 77-83.

Das, K., Debacker, V., Pillet, S., Bouquegneau, J.-M., 2003. Heavy metals in marine mammals. In: Vos, J.G., Bossart, G., Fournier, M., O’Shea, T. (Eds.), Toxicology of Marine Mammals. Taylor and Francis Publishers, Washington, DC, pp. 135-167.

Das, K., Siebert, U., Gillet, A., Dupont, A., Di-Poï, C., Fonfara, S., Mazzucchelli, G., De Pauw, E., De Pauw-Gillet, M.-C., 2008. Mercury immune toxicity in harbour seals: links to in vitro toxicity. Environ. Health, 7.

De Guise, S., 2002. Cellular immunology of cetaceans. In: Pfeiffer, C.J. (Ed.), Molecular and Cell Biology of Marine Mammals. Krieger Publishing Company, Melbourne, Florida, pp. 235-244.

De Guise, S., Martineau, D., Béland, P., Fournier, M., 1998. Effects of in vitro exposure of beluga whale leucocytes to selected organochlorines. J. Toxicol. Environ. Health A 55, 479-493.

De Guise, S., Beckmen, K.B., Holladay, S.D., 2003. Contaminants and marine mammal immunotoxicology and pathology. In: Vos, J.G., Bossart, G.D., Fournier, M. O'Shea, T.J.(Eds.), Toxicology of Marine Mammals. New Perspectives: Toxicology and the Environment. Taylor and Francis, London, pp. 38-54.

de Swart, R.L., Kluten, R.M.G., Huizing, C.J., Vedder, L.J., Reijnders, P.J.H., Visser, I.K.G., UytdeHaag, F.G.C.M., Osterhaus, A.D.M.E., 1993. Mitogen and antigen induced B and $\mathrm{T}$ cell responses of peripheral blood mononuclear cells from the harbour seal (Phoca vitulina). Vet. Immunol. Immunopathol. 37, 217-230.

de Swart, R.L., Harder, T.C., Ross, P.S., Vos, H.W., Osterhaus, A.D.M.E., 1995a. Morbilliviruses and morbillivirus diseases of marine mammals. Infect. Agents Dis. 4 $125-130$.

de Swart, R.L., Ross, P.S., Timmerman, H.H., Hijman, W.C., de Ruiter, E.M., Liem, A.K.D., Brouwer, A., van Loveren, H., Reijnders, P.J.H., Vos, J.G., Osterhaus, A.D.M.E. 
1995b. Short term fasting does not aggravate immunosuppression in harbour seals (Phoca vitulina) with high body burdens of organochlorines. Chemosphere 31, 4289-4306.

de Swart, R.L., Ross, P.S., Vedder, L.J., Boink, F.B.T.H., Reijnders, P.J.H., Mulder, P.G.H., Osterhaus, A.D.M.E., 1995c. Haematology and clinical chemistry values for harbour seals (Phoca vitulina) fed environmentally contaminated herring remain within normal ranges. Can. J. Zool. 73, 2035-2043.

de Swart, R.L., Ross, P.S., Vos, J.G., Osterhaus, A.D.M.E., 1996. Impaired immunity in harbour seals (Phoca vitulina) exposed to bioaccumulated environmental contaminants: review of a long-term feeding study. Environ. Health Perspect. 104, 823-828.

Debier, C., Pomeroy, P.P., Dupont, C., Joiris, C., Comblin, V., Le Boulengé, E., Larondelle, Y., Thomé, J.-P., 2003. Quantitative dynamics of PCB transfer from mother to pup during lactation in UK grey seals Halichoerus grypus. Mar. Ecol. Prog. Ser. 247, 237-248

Dietz, R., Heide-Jørgensen, M.P., Harkonen, T., 1989. Mass deaths of harbor seals (Phoca vitulina) in Europe. Ambio 18, 258.

Dufresne, M.M., Frouin, H., Pillet, S., Lesage, V., De Guise, S., Fournier, M., 2010. Comparative sensitivity of harbour and grey seals to several environmental contaminants using in vitro exposure. Mar. Pollut. Bull. 60, 344-349.

Duignan, P.J., Saliki, J.T., St Aubin, D.J., Early, G., Sadove, S., House, J.A., Kovacs, K., Geraci, J.R., 1995. Epizootiology of morbillivirus infection in North American harbor seals (Phoca vitulina) and gray seals (Halichoerus grypus). J. Wildl. Dis. 31, 491-501.

Frouin, H., Lebeuf, M., Hammill, M., Masson, S., Fournier, M., 2010. Effects of individ ual polybrominated diphenyl ether (PBDE) congeners on harbour seal immune cells in vitro. Mar. Pollut. Bull. 60, 291-298.

Greenland, J.A., Limpus, C.J., 2007. Marine wildlife stranding and mortality database annual report 2007. II. Cetacean and Pinniped. In: Environmental Protection Agency, Conservation technical and data report., pp. 30.

Griesel, S., Mundry, R., Kakuschke, A., Fonfara, S., Siebert, U., Prange, A., 2006. Mineral elements and essential trace elements in blood of seals of the North Sea measured by total-reflection X-ray fluorescence analysis. Spectrochim. Acta B: Atom. Spectrosc. 61, 1158-1165.

Griesel, S., Kakuschke, A., Siebert, U., Prange, A., 2008. Trace element concentrations in blood of harbor seals (Phoca vitulina) from the Wadden Sea. Sci. Total Environ. 392, 313-323.

Habran, S., Debier, C., Crocker, D.E., Houser, D.S., Das, K., 2011. Blood dynamics of mercury and selenium in northern elephant seals during the lactation period. Environ. Pollut. 159, 2523-2529.

Habran, S., Pomeroy, P.P., Debier, C., Das, K., 2013. Changes in trace elements during lactation in a marine top predator, the grey seal. Aquat. Toxicol. 126, 455-466.

Hanni, K.D., Long, D.J., Jones, R.E., Pyle, P., Morgan, L.E., 1997. Sightings and strandings of Guadalupe fur seals in central and northern California, 1988-1995. J. Mammal. 78, 684-690.

Härkönen, T., Dietz, R., Reijnders, P., Teilmann, J., Harding, K., Hall, A., Brasseur, S., Siebert, U., Goodman, S.J., Jepson, P.D., Rasmussen, T.D., Thompson, P., 2006. The 1988 and 2002 phocine distemper virus epidemics in European harbour seals. Dis. Aquat. Organ. 68, 115-130.

Hasselmeier, I., Fonfara, S., Driver, J., Siebert, U., 2008. Differential hematology profiles of free-ranging, rehabilitated, and captive harbor seals (Phoca vitulina) of the German North Sea. Aquat. Mamm. 34, 149-156.

Henderson, R.J., Kalogeropoulos, N., Alexis, M., 1994. The lipid composition of selected tissues from a Mediterranean monk seal, Monachus monachus. Lipids 29, 577-582.

Jepson, P.D., Bennett, P.M., Deaville, R., Allchin, C.R., Baker, J.R., Law, R.J., 2005. Relationships between polychlorinated biphenyls and health status in harbor porpoises (Phocoena phocoena) stranded in the United Kingdom. Environ. Toxicol. Chem. 24, 238-248

Kakuschke, A., Prange, A., 2007. The influence of metal pollution on the immune system a potential stressor for marine mammals in the north sea. Int. J. Comp. Psychol. 20, 179-193.

Kakuschke, A., Valentine-Thon, E., Griesel, S., Fonfara, S., Siebert, U., Prange, A., 2005 Immunological impact of metals in harbor seals (Phoca vitulina) of the North Sea. Environ. Sci. Technol. 39, 7568-7575.

Kakuschke, A., Valentine-Thon, E., Griesel, S., Rosenberger, T., Mundry, R., Siebert, U., Prange, A., 2008. Blood metal levels and metal-influenced immune functions of harbour seals in captivity. Mar. Pollut. Bull. 56, 764-769.

Kannan, K., Blankenship, A.L., Jones, P.D., Giesy, J.P., 2000. Toxicity reference values for toxic effects of polychlorinated biphenyls to aquatic mammals. Hum. Ecol. Risk Assess. 6, 181-201.

Lahvis, G.P., Wells, R.S., Kuehl, D.W., Stewart, J.L., Rhinehart, H.L., Via, C.S., 1995. Decreased lymphocyte responses in free-ranging bottlenose dolphins (Tursiops truncatus) are associated with increased concentrations of PCBs and DDT in peripheral blood. Environ. Health Perspect. 103, 67-72.

Lang, D., Mueller-Ruchholtz, W., 1991. Human lymphocyte reactivity after in vitro exposure to technical and analytical grade pentachlorophenol. Toxicology 70, 271-282.

Levin, M., De Guise, S., Ross, P.S., 2005. Association between lymphocyte proliferation and polychlorinated biphenyls in free-ranging harbor seal (Phoca vitulina) pups from British Columbia, Canada. Environ. Toxicol. Chem. 24, 1247-1252.

Levin, M., Leibrecht, H., Mori, C., Jessup, D., De Guise, S., 2007. Immunomodulatory effects of organochlorine mixtures upon in vitro exposure of peripheral blood leucocytes differ between free-ranging and captive southern sea otters (Enhydra lutris). Vet. Immunol. Immunopathol. 119, 269-277.
Lipscomb, T.P., Kennedy, S., Moffett, D., Krafft, A., Klaunberg, B.A., Lichy, J.H., Regan, G.T., Worthy, G.A.J., Taubenberger, J.K., 1996. Morbilliviral epizootic in bottlenose dolphins of the Gulf of Mexico. J. Vet. Diagn. Invest. 8, 283-290.

Luebke, R.W., Hodson, P.V., Faisal, M., Ross, P.S., Grasman, K.A., Zelikoff, J., 1997. Aquatic pollution-induced immunotoxicity in wildlife species. Toxicol. Sci. 37 $1-15$.

Lydersen, C., Wolkers, H., Severinsen, T., Kleivane, L., Nordøy, E.S., Skaare, J.U., 2002 Blood is a poor substrate for monitoring pollution burdens in phocid seals. Sci. Total Environ. 292, 193-203.

Mori, C., Morsey, B., Levin, M., Nambiar, P.R., De Guise, S., 2006. Immunomodulatory effects of in vitro exposure to organochlorines on T-cell proliferation in marine mammals and mice. J. Toxicol. Environ. Health A: Curr. Iss. 69, 283-302.

Mos, L., Morsey, B., Jeffries, S.J., Yunker, M.B., Raverty, S., Guise, S.D., Ross, P.S., 2006. Chemical and biological pollution contribute to the immunological profiles of free-ranging harbor seals. Environ. Toxicol. Chem. 25, 3110-3117.

Muelbert, M.M.C., Bowen, W.D., 1993. Duration of lactation and postweaning changes in mass and body composition of harbour seal, Phoca vitulina, pups. Can. J. Zool. 71, 1405-1414.

Müller, G., Wohlsein, P., Beineke, A., Haas, L., Greiser-Wilke, I., Siebert, U., Fonfara, S., Harder, T., Stede, M., Gruber, A.D., Baumgärtner, W., 2004. Phocine distemper in German Seals, 2002. Emerg. Infect. Dis. 10, 723-725

Nakatsuru, S., Oohashi, J., Nozaki, H., Nakada, S., Imura, N., 1985. Effect of mercurials on lymphocyte functions in vitro. Toxicology 36, 297-306.

Neale, J.C.C., Van de Water, J.A., Harvey, J.T., Tjeerdema, R.S., Gershwin, M.E., 2002. Proliferative responses of harbor seal (Phoca vitulina) T lymphocytes to model marine pollutants. Dev. Immunol. 9, 215-221.

Nordoy, E.S., Blix, A.S., 1985. Energy sources in fasting grey seal pups evaluated with computed tomography. Am. J. Physiol. - Regul. Integr. Comp. Physiol. 249, R471-R476

O'Shea, T.J., Tanabe, S., 2003. Persistent ocean contaminants and marine mammals: a retrospective overview. In: Vos, J.G., Bossart, G.D., Fournier, M., O'Shea, T.J. (Eds.), Toxicology of Marine Mammals. Taylor \& Francis, London, New York, pp. 99-134.

Osinga, N., Shahi Ferdous, M.M., Morick, D., García Hartmann, M., Ulloa, J.A., Vedder, L., Udo de Haes, H.A., Brakefield, P.M., Osterhaus, A.D.M.E., Kuiken, T., 2012 Patterns of stranding and mortality in common seals (Phoca vitulina) and grey seals (Halichoerus grypus) in The Netherlands between 1979 and 2008. J. Comp. Pathol. 147, 550-565.

Pillet, S., Fournier, M., Measures, L.N., Bouquegneau, J.-M., Cyr, D.G., 2002. Presence and regulation of metallothioneins in peripheral blood leucocytes of grey seals. Toxicol. Appl. Pharmacol. 185, 207-217.

Reijnders, P.J.H., 1980. Organochlorine and heavy metal residues in harbour seals from the wadden sea and their possible effects on reproduction. Neth. J. Sea Res $14,30-65$

Reijnders, P.J.H., 1981. Management and conservation of the harbour seal, Phoca vitulina, population in the international wadden sea area. Biol. Conserv. 19, 213-221.

Rogan, E., Baker, J.R., Jepson, P.D., Berrow, S., Kiely, O., 1997. A mass stranding of white-sided dolphins (Lagenorhynchus acutus) in Ireland: biological and pathological studies. J. Zool. 242, 217-227.

Ross, P.S., 2002. The role of immunotoxic environmental contaminants in facilitating the emergence of infectious diseases in marine mammals. Hum. Ecol. Risk Assess. 8, 277-292.

Ross, P.S., De Swart, R., Addison, R., Van Loveren, H., Vos, J., Osterhaus, A., 1996a. Contaminant-induced immunotoxicity in harbour seals: wildlife at risk? Toxicology 112, 157-169.

Ross, P.S., De Swart, R.L., Timmerman, H.H., Reijnders, P.J.H., Vos, J.G., Van Loveren, H., Osterhaus, A.D.M.E., 1996b. Suppression of natural killer cell activity in harbour seals (Phoca vitulina) fed Baltic Sea herring. Aquat. Toxicol. 34, 71-84.

Ross, P.S., De Swart, R.L., Van Loveren, H., Osterhaus, A.D.M.E., Vos, J.G., 1996c. The immunotoxicity of environmental contaminants to marine wildlife: a review. Annu. Rev. Fish Dis. 6, 151-165.

Ross, P.S., Beckmen, K.B., Pillet, S., 2003a. Immunotoxicology of free-ranging pinnipeds: approaches to study design. In: Vos, J.G., Bossart, G., Fournier, M., O’Shea, T. (Eds.), Toxicology of Marine Mammals. Taylor and Francis Publishers, Washington, DC, pp. 570-591.

Ross, P.S., Vos, J.G., Osterhaus, A.D.M.E., 2003b. The immune system, environmental contaminants and virus-associated mass mortalities among pinnipeds. In: Vos, J.G., Bossart, G., Fournier, M., O'Shea, T. (Eds.), Toxicology of Marine Mammals. Taylor and Francis Publishers, Washington, DC, pp. 534-557.

Siebert, U., Wohlsein, P., Lehnert, K., Baumgartner, W., 2007. Pathological findings in harbour seals (Phoca vitulina): 1996-2005. J. Comp. Pathol. 137, 47-58.

Siebert, U., Heidmann, A., Friedhoff, N., Kruse, H., Rigét, F., Adler, S., Maser, E., 2012 Organochlorine burdens in harbour seals from the german wadden sea collected during two phocine distemper epizootics and ringed seals from west greenland waters. J. Environ. Anal. Toxicol. 2, 2-8.

Sinjari, T., Klasson-Wehler, E., Oskarsson, A., Darnerud, P.O., 1996. Milk transfer and neonatal uptake of coplanar polychlorinated biphenyl (PCB) congeners in mice. Pharmacol. Toxicol. 78, 181-186.

Stone, K.D., Feldman, H.A., Huisman, C., Howlett, C., Jabara, H.H., Bonilla, F.A., 2009. Analysis of in vitro lymphocyte proliferation as a screening tool for cellular immunodeficiency. Clin. Immunol. 131, 41-49.

van Loveren, H., Ross, P.S., Osterhaus, A.D.M.E., Vos, J.G., 2000. Contaminant-induced immunosuppression and mass mortalities among harbour seals. Toxicol. Lett. 112-113, 319-324. 
Vanden Berghe, M., Weijs, L., Habran, S., Das, K., Bugli, C., Rees, J.-F., Pomeroy, P., Covaci, A., Debier, C., 2012. Selective transfer of persistent organic pollutants and their metabolites in grey seals during lactation. Environ. Int. 46, 615.

Vermes, I., Haanen, C., Steffens-Nakken, H., Reutellingsperger, C., 1995. A novel assay for apoptosis flow cytometric detection of phosphatidylserine expression on early apoptotic cells using fluorescein labelled Annexin V. J. Immunol. Methods 184, 39-51.

Vos, J.G., Ross, P.S., de Swart, R.L., van Loveren, H., Osterhaus, A.D.M.E., 2003. The effects of chemical contaminants on immune function in harbor seals: results of a semi-field study. In: Vos, J.G., Bossart, G.D., Fournier, M., O’Shea, T.J. (Eds.), Toxicology of Marine Mammals, New Perspectives: Toxicology and the Environment. Taylor and Francis, pp. 558-591.

Weijs, L., Das, K., Siebert, U., van Elk, N., Jauniaux, T., Neels, H., Blust, R., Covaci, A. 2009a. Concentrations of chlorinated and brominated contaminants and their metabolites in serum of harbour seals and harbour porpoises. Environ. Int. 35, $842-850$.
Weijs, L., Dirtu, A.C., Das, K., Gheorghe, A., Reijnders, P.J.H., Neels, H., Blust, R. Covaci, A., 2009b. Inter-species differences for polychlorinated biphenyls and polybrominated diphenyl ethers in marine top predators from the Southern North Sea: Part 1. Accumulation patterns in harbour seals and harbour porpoises. Environ. Pollut. 157, 437-444.

Weijs, L., Dirtu, A.C., Das, K., Gheorghe, A., Reijnders, P.J.H., Neels, H., Blust, R., Covaci A., 2009c. Inter-species differences for polychlorinated biphenyls and polybrominated diphenyl ethers in marine top predators from the Southern North Sea: Part 2. Biomagnification in harbour seals and harbour porpoises. Environ. Pollut. 157, 445-451.

Weijs, L., Covaci, A., Yang, R.S.H., Das, K., Blust, R., 2011. A non-invasive approach to study lifetime exposure and bioaccumulation of PCBs in protected marine mammals: PBPK modeling in harbor porpoises. Toxicol. Appl. Pharmacol. 256 136-145.

Zharinov, A., Tarasov, P., Shvalov, A., Semyanov, K., van Bockstaele, D.R., Maltsev, V., 2006. A study of light scattering of mononuclear blood cells with scanning flow cytometry. J. Quant. Spectrosc. Radiat. Transfer 102, 121-128. 